\title{
An Experimental Study on Measurement Methods of Bulk Density and Porosity of Rock Samples
}

\author{
Weiren Lin ${ }^{*}$, Osamu Tadai², Manabu Takahashi' ${ }^{3}$, Daisaku Sato ${ }^{4}$, Takehiro Hirose1, \\ Wataru Tanikawa1, Yohei Hamada1, Kentaro Hatakeda ${ }^{2}$ \\ ${ }^{1}$ Kochi Institute for Core Sample Research, Japan Agency for Marine-Earth Science and Technology, Nankoku, \\ Japan \\ ${ }^{2}$ Department of Marine \& Earth Sciences, Marine Works Japan Ltd., Nankoku, Japan \\ ${ }^{3}$ Research Institute of Earthquake and Volcano Geology, National Institute of Advanced Industrial Science and \\ Technology, Tsukuba, Japan \\ ${ }^{4}$ Graduate School of International and Area Studies, Hankuk University of Foreign Studies, Seoul, Korea \\ Email: ${ }^{*}$ lin@jamstec.go.jp
}

Received 29 May 2015; accepted 10 July 2015; published 17 July 2015

\begin{abstract}
Density and porosity are fundamental and important physical properties of rocks in various geological problems, and affect the other physical properties. Therefore, measurements of density and porosity of rock samples are important investigation items in both geo-science and geo-engineering areas. Several measurement techniques of the density and porosity are available and being applied currently. To ensure the data quality and to conduct its quality assessment, comparison of measurement results by different measurement techniques is necessary since the techniques are based on different principles and test procedures. In this study, we collected eight types of rock samples including a gabbro, a granite, four sandstones, a welded tuff and a mudstone as study materials, and also prepared several metal specimens for the experimental comparison. The porosities of the eight rocks covered a very wide range from $0.3 \%$ to $50 \%$ approximately. We employed three methods (caliper, buoyancy and helium-displacement pycnometer) to measure volumes of regularly-shaped specimens and to determine their bulk densities and porosities. As a result, the three techniques yielded almost same bulk densities and porosities for all the specimens. In addition, we also applied mercury intrusion porosimetry to measure density and porosity as well as to determine pore size distribution of the rock samples. Porosity values obtained by the porosimetry method were underestimated in the case of high-porosity (soft) rock samples and overestimated for the very low-porosity rock samples. Ability to determine pore size distribution, however, is a very important advantage of the porosimetry method.
\end{abstract}

\section{Keywords}

Rock, Density, Porosity, Caliper Method, Buoyancy Method, Helium-Displacement Pycnometer, Mucury Intrusion Posimetry

\footnotetext{
${ }^{*}$ Corresponding author.
} 


\section{Introduction}

Density and porosity are fundamental and important physical properties of rocks in various geological problems, and affect the other physical properties such as elastic wave velocity, permeability, resistivity, strength, Young's modulus etc. (e.g. Schon 1998) [1]. Therefore, measurements of density and porosity using drilling core samples retrieved from depths and rock samples taken from geological outcrops are the most popular and important investigation items in both geo-science and geo-engineering fields. Several measurement techniques of bulk density and porosity are available and currently applied in the fields (Franclin, 1979) [2]. To ensure the data quality, comparison and examination of the measurement results by the different measurement techniques are necessary since the techniques are based on different principles and test procedures. In this experimental study, for comparison of measurement results we collected eight types of rock samples including a gabbro, a granite, four sandstones, a welded tuff and a mudstone as test materials, and also several metal samples and then measured the density and porosity of the rock samples by different techniques. The porosities of the eight rocks covered a very wide range from $0.3 \%$ to $50 \%$ approximately. We employed three methods (caliper, buoyancy and helium-displacement pycnometer also called gas pycnometer) to measure volume of regularly-shaped specimens and to determine the bulk densities and porosities of the rock samples (Franclin, 1979 and Blum, 1997) [2] [3]. In addition, we also measured the porosities and determined pore size distributions by mercury intrusion porosimetry (American Society for Testing and Materials, 1999) [4].

\section{Rock Samples and Test Methods}

\subsection{Samples}

As test materials for the planned experiments of different methods, eight types of rock samples which cover a very wide porosity range were collected. The rock types of the samples are middle-grained Belfast gabbro (Symbol used in this study: BG) retrieved from South Africa, fine-grained Aji Granite (AG) from Kagawa Pref., Japan, an yellow sandstone (AAS) from Australia, Rajasthan sandstone (RS) from India, Shirahama sandstone (SS) from Wakayama Pref., Japan, Berea sandstone (BS) from Ohio State, USA, Tage welded tuff (TWT) from Tochigi Pref., Japan and Nankai mudstone (NM) from an off shore ocean drilling site in southwest Japan.

The Nankai mudstone was obtained by a scientific deep ocean drilling project from a depth of 476 meters below sea floor with about $3800 \mathrm{~m}$ water depth at IODP (Integrated Ocean Drilling Program) drilling site C0006F in west Pacific Ocean (Expedition 314 Scientists, 2009) [5]. The other rocks were taken from quarries on land. All of the rock samples are relative homogenous and fresh, e.g., not weathered and visual crack free. The rock types and number of specimens used for various experiments were shown in Table 1. Addition to the rock samples, we also prepared five metal specimens (two aluminum, two brass and one stainless specimens) for the volume measurements because they do not have pore and are regularly shaped in a better quality than rock samples.

Table 1. Rock types and number of test specimens for the various experiments.

\begin{tabular}{ccccc}
\hline \multirow{2}{*}{ Sample Type } & \multicolumn{3}{c}{ Specimen number for individual method } \\
\cline { 2 - 5 } & Caliper method & Buoyancy method & Pycnometer & Porosimetry \\
\hline Belfast gabbro [BG] & 6 & 6 & 3 & 2 \\
Aji granite [AG] & 6 & 6 & 3 & 2 \\
Australia A Sandstone [AAS] & 3 & 3 & 3 & 2 \\
Rajasthan Sandstone [RS] & 3 & 3 & 3 & 2 \\
Shirahama Sandstone [SS] & 3 & 3 & 3 & 2 \\
Berea Sandstone [BS] & 3 & 3 & 3 & 2 \\
Tage Welded Tuff [TWT] & 3 & 3 & 3 & 2 \\
Nankai Mudstone [NM] & - & 3 & 5 & - \\
Metals & 5 & 5 & 3 & \\
\hline
\end{tabular}


We prepared rock specimens for the measurements in a shape of regular cylinder for seven rock types except the NM. Sizes of all the cylinder specimens are of the same diameter (approximately $25 \mathrm{~mm}$ ), but of different length of 20 - $35 \mathrm{~mm}$ dependent on the original rock sample size. Because the dimension of NM drilling core sample was not enough for recoring to make up the 25 mm-diameter cylindrical specimens, we used irregular specimens for NM.

\subsection{Measurement Methods and Procedures}

For determining bulk density of rock samples, the simplest method is to measure their volume and mass (or weight) as showed in Equation (1);

$$
\square \rho_{B}=M / V_{B}
$$

where $\rho_{B}$ is bulk density $\left(\mathrm{g} / \mathrm{cm}^{3}\right), M$ is mass $(\mathrm{g})$, and $V_{B}$ is the bulk volume including both solid's and pore's volume $\left(\mathrm{cm}^{3}\right)$. If mass $M$ was measured using dry rock specimen, $\rho_{B}$ is the bulk dry density. On the other hand, bulk wet density is determined by the mass of the rock specimen at water saturated state. In this study, we deal with the bulk dry density. Porosity ( $n$ in \%) is defined as the ratio of accumulated (total) pore volume $\left(V_{P}\right.$ in $\left.\mathrm{cm}^{3}\right)$ included in a rock specimen to the bulk volume $V_{B}$ of the specimen as follow:

$$
n=100 \times V_{P} / V_{B}
$$

Based on these equations, it is clear that the measurements of bulk volume and pore volume control measurement accuracy of density and porosity of rock specimens rather than mass (or weight) measurements which can be performed by an electrical balance relatively easily and accurately. Therefore, to examine results of volume measurements by different methods is the key issue.

For bulk volume measurements, three methods i.e. caliper (Franclin, 1979; resolution of the caliper used: 0.05 mm) [2], buoyancy based on Archimedes’ principle (Franclin, 1979; US620H and SMK-102 of Shimadzu Corporation, Japan) [2], and helium-displacement Penta-Pycnometer which is according to Boyle's Law (Blum, 1997; Pentapycnometer of Quantachrome Corporation, USA) [3], were employed in this study.

First, the rock specimens were soaked in a vacuumed desiccator for about three days for water saturation. Then, their bulk volumes were independently measured by the three methods; and their weights at wet state by an electrical balance with $0.001 \mathrm{~g}$ resolution. After these measurements, the specimens were dried in an oven at $110^{\circ} \mathrm{C}$ for more than 24 hours. After cooling the specimens to the room temperature in a dried desiccator, their dry weights were measured by the same electrical balance and dry volumes (volumes of solid portion only) were determined by pycnometer. We use the following equation to determine pore volume $V_{P}\left(\mathrm{~cm}^{3}\right)$ :

$$
V_{P}=\left(M_{\text {wet }}-M_{d r y}\right) / \rho_{\text {water }}
$$

where $M_{\text {wet }}(\mathrm{g})$ is the mass of the specimen at water saturated state, $M_{d r y}(\mathrm{~g})$ is the mass at dry state and $\rho_{\text {water }}$ $\left(\mathrm{g} / \mathrm{cm}^{3}\right)$ is the water density at the room temperature.

Here, we use the same rock specimens for the different measurement methods, and believe it is important for such experimental comparison studies of different measurement methods. After the measurements of caliper, buoyancy and pycnometer methods; the specimens used were finally resized (cut) to fit sample holder of the mercury intrusion porosimetry apparatus (Mercury Porosimeter Auto Pore IV 9500 of Micromeritics, USA). Then, the pore volumes and pore size distributions in dry specimens were determined by the porosimetry method (American Society for Testing and Materials, 1999) [4].

\section{Measurement Results and Discussions}

\subsection{Bulk Volume Measured by Different Methods}

The all bulk volume data of the eight rock types and metal specimens measured independently by the caliper, buoyancy and pycnometer methods were listed in Table 2. Pycnometer measurements were carried out at both wet and dry states of the rock specimens, respectively. Because the measured volume at dry state is corresponding the volume of solid portion only, the bulk volume (including both solid and pore volumes) can be calculated by adding the measured solid volume to the pore water volume obtained from the difference between wet and dry specimen weights. 
Table 2. A comparison of bulk volumes measured by different methods.

\begin{tabular}{|c|c|c|c|c|c|c|c|}
\hline \multirow[b]{2}{*}{$\begin{array}{l}\text { Sample } \\
\text { Type }\end{array}$} & \multirow[b]{2}{*}{ Specimen ID } & \multicolumn{4}{|c|}{ Bulk volume $\left(\mathrm{cm}^{3}\right)$} & \multirow[b]{2}{*}{$\begin{array}{c}\text { Pore } \\
\text { volume } \\
\left(\mathrm{cm}^{3}\right)\end{array}$} & \multirow{2}{*}{$\begin{array}{c}\text { Solid } \\
\text { volume } \\
\text { (Pycnometer, } \\
\text { dry) } \\
\left(\mathrm{cm}^{3}\right)\end{array}$} \\
\hline & & $\begin{array}{l}\text { Caliper } \\
\text { method }\end{array}$ & $\begin{array}{c}\text { Buoyancy } \\
\text { method }\end{array}$ & $\begin{array}{l}\text { Pycnometer } \\
\text { (wet) }\end{array}$ & $\begin{array}{c}\text { Solid volume } \\
+ \\
\text { Pore volume }\end{array}$ & & \\
\hline \multirow{6}{*}{$\begin{array}{c}\text { Belfast } \\
\text { gabbro [BG] }\end{array}$} & BG-1 & 17.51 & 17.45 & 17.45 & 17.46 & 0.03 & 17.42 \\
\hline & BG-2 & 17.08 & 16.99 & 16.97 & 17.03 & 0.03 & 17.00 \\
\hline & BG-3 & 16.74 & 16.63 & 16.54 & 16.62 & 0.03 & 16.59 \\
\hline & BG-4 & 11.25 & 11.27 & & & 0.02 & \\
\hline & BG-5 & 9.63 & 9.62 & & & 0.02 & \\
\hline & BG-6 & 8.90 & 8.90 & & & 0.02 & \\
\hline \multirow{6}{*}{$\begin{array}{c}\text { Aji granite } \\
\text { [AG] }\end{array}$} & AG-1 & 18.59 & 18.52 & 17.96 & 18.55 & 0.14 & 18.41 \\
\hline & AG-2 & 18.21 & 18.14 & 17.50 & 18.20 & 0.17 & 18.03 \\
\hline & AG-3 & 17.77 & 17.69 & 17.02 & 17.72 & 0.15 & 17.57 \\
\hline & $A G-4$ & 10.05 & 10.03 & & & 0.07 & \\
\hline & AG-5 & 9.58 & 9.50 & & & 0.06 & \\
\hline & AG-6 & 8.93 & 8.93 & & & 0.06 & \\
\hline \multirow{3}{*}{$\begin{array}{c}\text { Australia A } \\
\text { Sandstone } \\
\text { [AAS] }\end{array}$} & AAS-1 & 17.83 & 17.73 & 17.08 & 17.26 & 1.49 & 15.77 \\
\hline & AAS-2 & 17.66 & 17.51 & 16.86 & 17.00 & 1.70 & 15.30 \\
\hline & AAS-3 & 15.85 & 15.74 & 15.02 & 15.18 & 1.18 & 14.00 \\
\hline \multirow{3}{*}{$\begin{array}{c}\text { Rajasthan } \\
\text { Sandstone } \\
\text { [RS] }\end{array}$} & RS-1 & 17.67 & 17.52 & 16.80 & 17.32 & 1.85 & 15.48 \\
\hline & RS-2 & 17.63 & 17.51 & 16.76 & 17.30 & 1.86 & 15.44 \\
\hline & RS-3 & 17.48 & 17.36 & 16.63 & 17.15 & 1.87 & 15.28 \\
\hline \multirow{3}{*}{$\begin{array}{l}\text { Shirahama } \\
\text { Sandstone } \\
\text { [SS] }\end{array}$} & SS-1 & 17.17 & 17.09 & 16.04 & 16.78 & 2.27 & 14.51 \\
\hline & SS-2 & 16.31 & 16.24 & 15.06 & 15.99 & 2.16 & 13.83 \\
\hline & SS-3 & 14.97 & 14.87 & 14.11 & 14.59 & 2.08 & 12.51 \\
\hline \multirow{3}{*}{$\begin{array}{c}\text { Berea } \\
\text { Sandstone } \\
\text { [BS] }\end{array}$} & BS-1 & 16.25 & 16.01 & 15.43 & 15.93 & 3.09 & 12.84 \\
\hline & BS-2 & 15.80 & 15.53 & 14.79 & 15.39 & 3.09 & 12.30 \\
\hline & BS-3 & 14.78 & 14.57 & 13.83 & 14.41 & 2.91 & 11.50 \\
\hline \multirow{3}{*}{$\begin{array}{c}\text { Tage } \\
\text { Welded Tuff } \\
\text { [TWT] }\end{array}$} & TWT-1 & 15.46 & 15.47 & 14.86 & 15.48 & 4.87 & 10.60 \\
\hline & TWT-2 & 15.17 & 15.17 & 14.44 & 15.13 & 4.81 & 10.32 \\
\hline & TWT-3 & 14.09 & 14.11 & 13.37 & 14.18 & 4.60 & 9.58 \\
\hline \multirow{3}{*}{$\begin{array}{c}\text { Nankai } \\
\text { Mudstone } \\
\text { [NM] }\end{array}$} & NM-1 & & 9.09 & 8.19 & 9.06 & 4.46 & 4.60 \\
\hline & NM-2 & - & 8.79 & 7.80 & 8.79 & 4.32 & 4.48 \\
\hline & NM-3 & & 8.30 & 7.45 & 8.27 & 4.06 & 4.22 \\
\hline \multirow{5}{*}{ Metals } & Aluminum 1 & 14.63 & 14.50 & 14.59 & & & \\
\hline & Aluminum 2 & 25.34 & 25.23 & 25.43 & & & \\
\hline & Brass 1 & 14.37 & 14.29 & 14.35 & - & - & - \\
\hline & Brass 2 & 25.06 & 24.98 & 25.22 & & & \\
\hline & Stainless & 14.98 & 14.98 & 14.96 & & & \\
\hline
\end{tabular}

Figure 1 is cross plots of the bulk volumes measured by buoyancy and the other methods, showing that the bulk volume values located in the vicinity of 1:1 line approximately. In detail, the values by pycnometer at wet state (blue circles) look like to be slightly smaller than the buoyancy method.

To make a quantitative comparison among the bulk volumes obtained by different methods, we defined a parameter "error" $E$ (\%) as follow:

$$
E=100 \times\left(V_{B}-V_{B-B}\right) / V_{B-B}
$$

where $V_{B}$ : the bulk volume obtained by individual method; $V_{B-B}$ : the bulk volume by the buoyancy method. This parameter in percentage more clearly shows how much different between the individual and buoyancy measurements (Figure 2).

Basically, the bulk volumes of metal specimens (Aluminum, Brass and Stainless) by the three methods are well consistent with each other; the differences were less than $1 \%$. For the rock specimens, if the specimen surface is not smooth caliper may measure "convex" parts, then showed slightly larger values than the buoyancy method. Within the two pycnometer measurements, the dry one shows a better agreement with the buoyancy and 


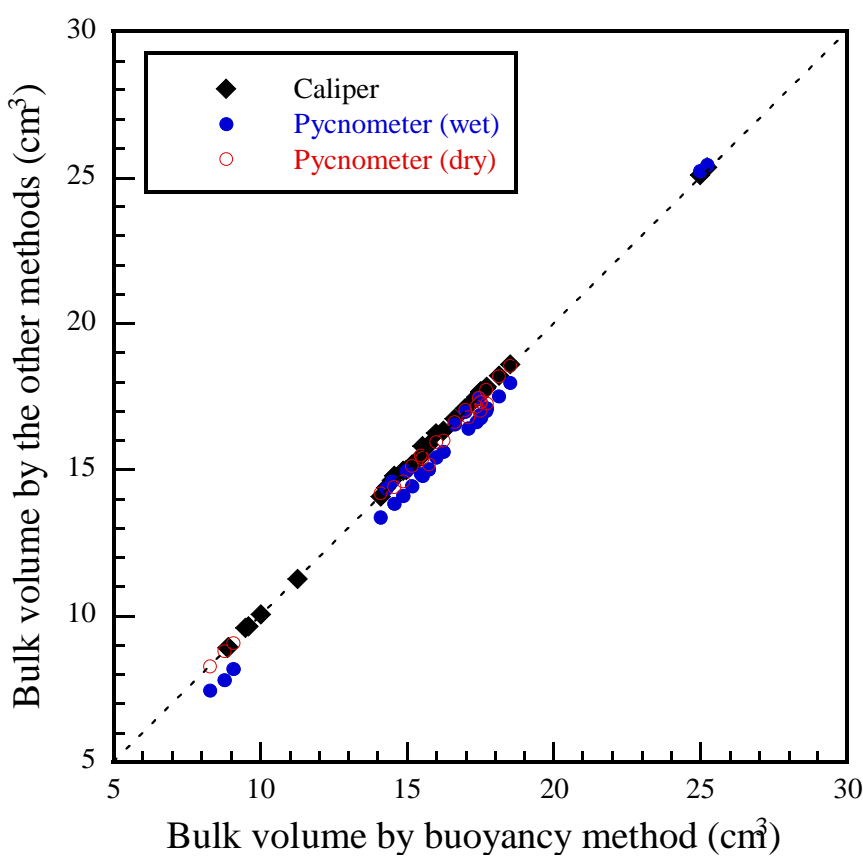

Figure 1. A comparison between bulk volumes measured by buoyancy and the other methods.

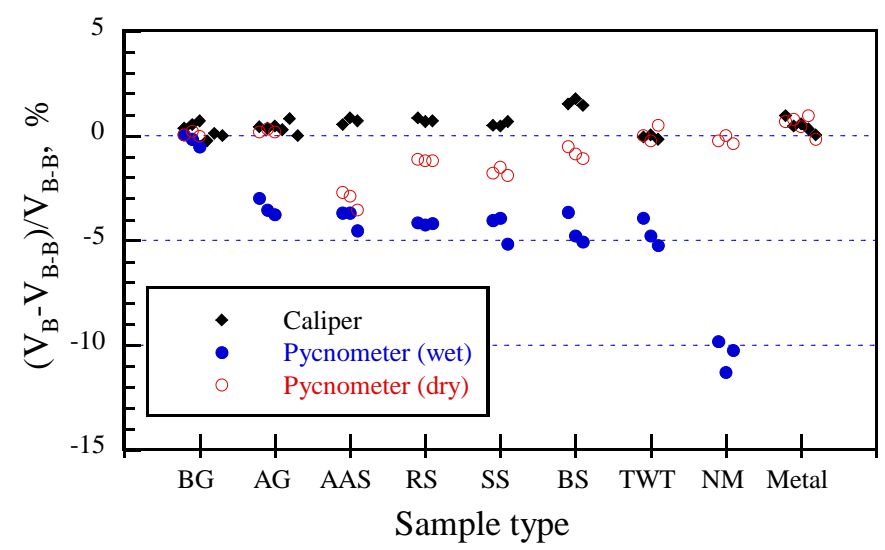

Figure 2. A quantitative comparison among the bulk volumes obtained by different methods.

caliper methods. The wet one, however, had approximately 5\% errors for six rocks except BG and NM. From this result, it can be considered that the pycnometer measurement using the dry specimen seems to be better than using the wet one. In addition, a trend showing the error level of the wet pycnometer data increases with the water content should be noted.

\subsection{Bulk Density and Porosity Measured by Different Methods}

We determined bulk dry densities of all the rock and metal specimens and porosities of the rock specimens by the different methods (Table 3). The densities were calculated based on the bulk volumes (Table 2) and specimen masses (weights) at dry state measured by the electrical balance according to Equation (1); and the porosities based on the mass (weight) difference between wet and dry states and the same bulk volumes by Equation (2). Mercury intrusion porosimetry also yields the porosity by measuring mercury volume injected into the rock specimens at high pressures; and bulk dry density using bulk volumes measured by the apparatus based on mercury displacement principle. 
Table 3. A comparison of bulk dry densities and porosities measured by various techniques.

\begin{tabular}{|c|c|c|c|c|c|c|c|c|}
\hline \multirow{2}{*}{$\begin{array}{l}\text { Sample } \\
\text { Type }\end{array}$} & \multirow[b]{2}{*}{ Specimen ID } & \multicolumn{4}{|c|}{ Bulk dry density $\left(\mathrm{g} / \mathrm{cm}^{3}\right)$} & \multicolumn{3}{|c|}{ Porosity (\%) } \\
\hline & & $\begin{array}{l}\text { Caliper } \\
\text { method }\end{array}$ & $\begin{array}{c}\text { Buoyancy } \\
\text { method }\end{array}$ & $\begin{array}{l}\text { Pycnometer } \\
\text { (dry) }\end{array}$ & Porosimetry & $\begin{array}{c}\text { Buoyancy } \\
\text { method }\end{array}$ & $\begin{array}{l}\text { Pycnometer } \\
\text { (dry) }\end{array}$ & Porosimetry \\
\hline \multirow{7}{*}{$\begin{array}{c}\text { Belfast } \\
\text { gabbro } \\
\text { [BG] }\end{array}$} & BG-1 & 2.942 & 2.954 & 2.952 & & 0.20 & 0.20 & \\
\hline & BG-2 & 2.942 & 2.958 & 2.952 & & 0.18 & 0.18 & \\
\hline & BG-3 & 2.921 & 2.941 & 2.942 & & 0.19 & 0.19 & \\
\hline & BG-4 & 2.952 & 2.945 & & 2.940 & 0.21 & & 0.35 \\
\hline & BG-5 & 2.942 & 2.945 & & 2.935 & 0.24 & & 0.35 \\
\hline & BG-6 & 2.940 & 2.945 & & & 0.24 & & \\
\hline & Average & 2.940 & 2.948 & 2.949 & 2.937 & 0.21 & 0.19 & 0.35 \\
\hline \multirow{7}{*}{$\begin{array}{c}\text { Aji } \\
\text { granite } \\
\text { [AG] }\end{array}$} & AG-1 & 2.635 & 2.647 & 2.643 & & 0.76 & 0.75 & \\
\hline & AG-2 & 2.636 & 2.647 & 2.638 & & 0.95 & 0.95 & \\
\hline & AG-3 & 2.635 & 2.648 & 2.643 & & 0.85 & 0.85 & \\
\hline & AG-4 & 2.639 & 2.646 & & 2.633 & 0.70 & & 0.66 \\
\hline & AG-5 & 2.625 & 2.647 & & 2.633 & 0.63 & & 0.66 \\
\hline & AG-6 & 2.641 & 2.642 & & & 0.63 & & \\
\hline & Average & 2.635 & 2.646 & 2.641 & 2.633 & 0.75 & 0.85 & 0.66 \\
\hline \multirow{4}{*}{$\begin{array}{c}\text { Australia } \\
\text { A } \\
\text { Sandstone } \\
\text { [AAS] }\end{array}$} & AAS-1 & 2.406 & 2.419 & 2.485 & 2.398 & 8.39 & 8.62 & 10.87 \\
\hline & AAS-2 & 2.360 & 2.380 & 2.451 & 2.409 & 9.72 & 10.01 & 10.51 \\
\hline & AAS-3 & 2.405 & 2.422 & 2.510 & & 7.48 & 7.76 & \\
\hline & Average & 2.390 & 2.407 & 2.482 & 2.403 & 8.53 & 8.80 & 10.69 \\
\hline \multirow{4}{*}{$\begin{array}{c}\text { Rajasthan } \\
\text { Sandstone } \\
\text { [RS] }\end{array}$} & RS-1 & 2.325 & 2.345 & 2.372 & 2.349 & 10.55 & 10.67 & 10.54 \\
\hline & RS-2 & 2.327 & 2.343 & 2.371 & 2.337 & 10.60 & 10.72 & 10.50 \\
\hline & RS-3 & 2.323 & 2.340 & 2.368 & & 10.77 & 10.90 & \\
\hline & Average & 2.325 & 2.342 & 2.370 & 2.343 & 10.64 & 10.76 & 10.52 \\
\hline \multirow{4}{*}{$\begin{array}{c}\text { Shiraham } \\
\text { a } \\
\text { Sandstone } \\
\text { [SS] }\end{array}$} & SS-1 & 2.275 & 2.286 & 2.328 & 2.291 & 13.28 & 13.52 & 14.15 \\
\hline & SS-2 & 2.273 & 2.283 & 2.319 & 2.285 & 13.30 & 13.50 & 13.78 \\
\hline & SS-3 & 2.268 & 2.283 & 2.327 & & 13.98 & 14.25 & \\
\hline & Average & 2.272 & 2.284 & 2.325 & 2.288 & 13.52 & 13.76 & 13.96 \\
\hline \multirow{4}{*}{$\begin{array}{c}\text { Berea } \\
\text { Sandstone } \\
\text { [BS] }\end{array}$} & BS-1 & 2.107 & 2.140 & 2.151 & 2.138 & 19.29 & 19.39 & 19.41 \\
\hline & BS-2 & 2.084 & 2.122 & 2.141 & 2.125 & 19.92 & 20.10 & 20.62 \\
\hline & BS-3 & 2.086 & 2.117 & 2.140 & & 19.96 & 20.17 & \\
\hline & Average & 2.093 & 2.126 & 2.144 & 2.131 & 19.72 & 19.89 & 20.02 \\
\hline \multirow{4}{*}{$\begin{array}{c}\text { Tage } \\
\text { Welded } \\
\text { Tuff } \\
\text { [TWT] }\end{array}$} & TWT-1 & 1.713 & 1.710 & 1.710 & 1.727 & 31.50 & 31.49 & 27.71 \\
\hline & TWT-2 & 1.713 & 1.712 & 1.717 & 1.747 & 31.71 & 31.79 & 28.59 \\
\hline & TWT-3 & 1,707 & 1.704 & 1.695 & & 32.59 & 32.42 & \\
\hline & Average & 1.711 & 1.709 & 1.707 & 1.737 & 31.93 & 31.90 & 28.15 \\
\hline \multirow{4}{*}{$\begin{array}{l}\text { Nankai } \\
\text { Mudstone } \\
\text { [NM] }\end{array}$} & NM-1 & & 1.373 & 1.392 & 1.454 & 49.14 & 49.26 & 43.56 \\
\hline & NM-2 & - & 1.372 & 1.387 & 1.409 & 49.09 & 49.09 & 44.39 \\
\hline & NM-3 & & 1.381 & 1.401 & & 48.83 & 49.03 & \\
\hline & Average & & 1.376 & 1.393 & 1.431 & 49.02 & 49.13 & 43.98 \\
\hline \multirow{5}{*}{ Metals } & Aluminum 1 & 2.655 & 2.680 & 2.663 & & & & \\
\hline & Aluminum 2 & 2.790 & 2.802 & 2.781 & & & & \\
\hline & Brass 1 & 8.441 & 8.488 & 8.453 & - & - & - & - \\
\hline & Brass 2 & 8.459 & 8.485 & 8.405 & & & & \\
\hline & Stainless & 7.867 & 7.870 & 7.882 & & & & \\
\hline
\end{tabular}

In a general sense, the bulk dry densities determined by the four methods were consistent well with each other (Table 3). For the porosities, the buoyancy method and pycnometer (dry) method showed almost the same values for all the rocks. The porosities by porosimetry, however, were larger than those of the other two methods for BG with very low porosity; and smaller for NM with very large porosity (Table 3). The difference for BG might be caused by the measurement accuracy of injected mercury volumes which are approximately $0.03 \mathrm{cc}$. 
On the other hand, the reason for the smaller porosity result for NM might be that high pressure applied for mercury injection causes deformation of the soft rock specimen and decrease its pore volume. Figure 3 shows a very good general relationship between the bulk dry density and the porosity of the eight rocks, i.e. the bulk dry density increases with the porosity decrease.

Although porosities obtained by the mercury porosimetry showed some uncertainty, it has a great advantage on measuring pore size distribution which could not be obtained by the other porosity measurement methods employed in this study (Lin et al., 2011) [6]. For example, the peak of pore size distribution of BS is around 10 $\mu \mathrm{m}$ being more than 100 times of that of NM although the porosity (43.56\%) of NM is much larger than that (19.41\%) of BS (Figure 4).

\section{Summary}

Several different measurement techniques of bulk density and porosity of rocks are available and being applied in the geo-science and geo-engineering fields. To ensure the data quality and to make its quality assessment, we carried out an experimental comparison study in which different measurement techniques (caliper, buoyancy, helium-displacement pycnometer and mercury intrusion porosimetry) were employed for the same rock specimens. We collected eight types of rock samples including a gabbro, a granite, four sandstones, a welded tuff and a mudstone as test materials. The porosities of the eight rocks covered a very wide range from $0.3 \%$ to $50 \%$ approximately. Therefore, it can be said that the collected rock samples are proper for such comparison study of different measurement techniques. As a result, the techniques using caliper, buoyancy and pycnometer yielded the almost same bulk dry density and porosity results. In detail, the helium-displacement pycnometer measurement

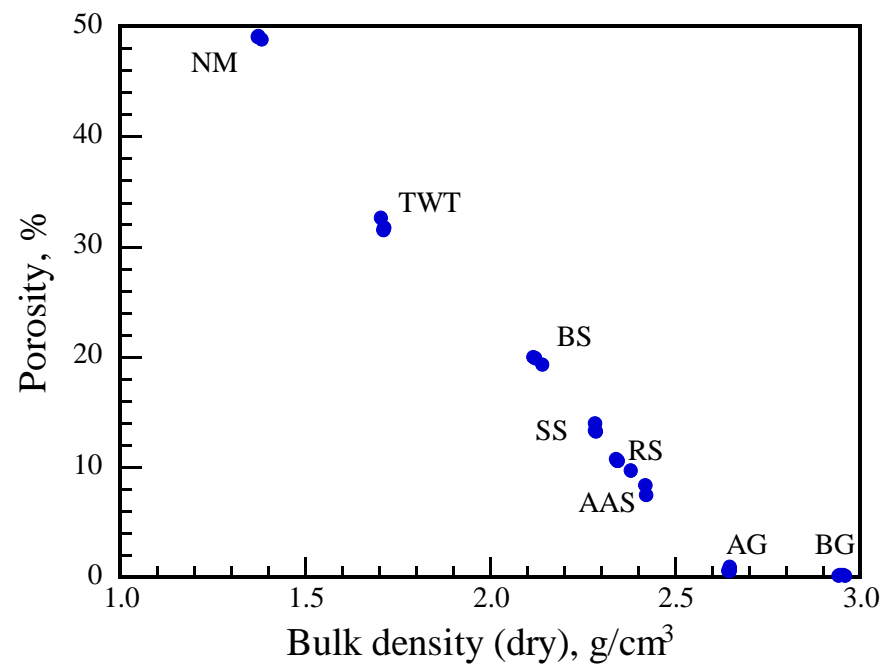

Figure 3. Relationship between porosity and bulk dry density measured by buoyancy method.
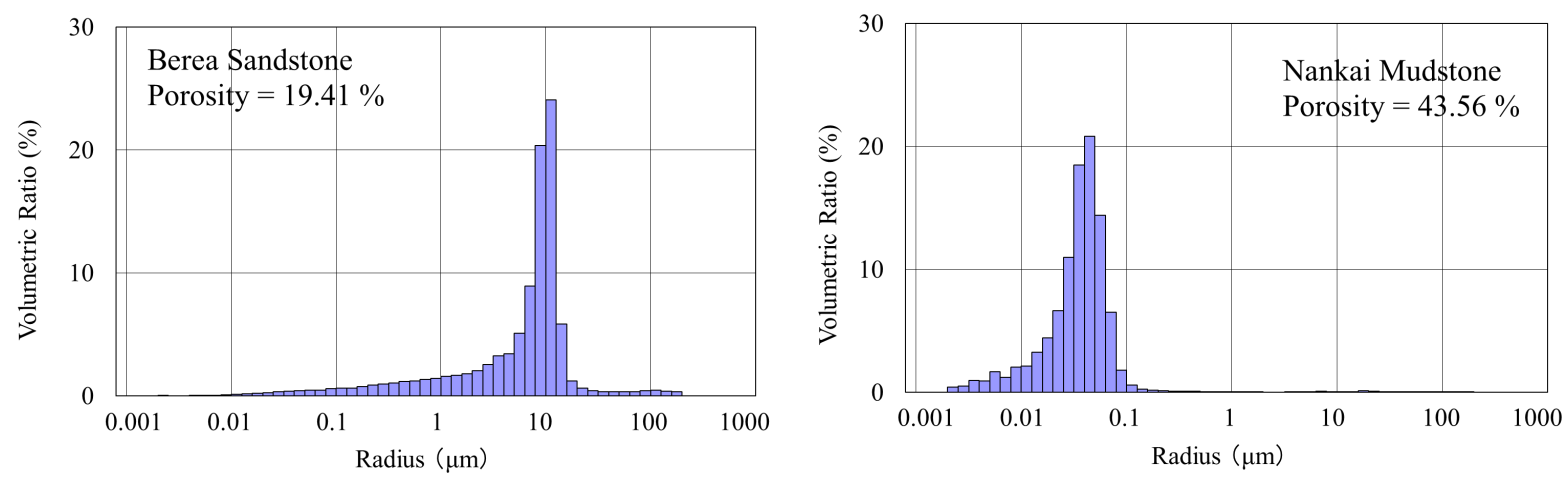

Figure 4. Two examples of pore size distribution obtained by mercury intrusion porosimetry. 
using the dry specimens seems to be better than using the wet ones. However, the porosimetry underestimated porosity values in the case of very high-porosity rock (i.e. soft rock) probably due to the specimen deformation under intrusion pressure; and showed some errors for the very low-porosity rock samples probably due to insufficient accuracy of mercury intrusion volume measurement. Ability to determine pore size distribution is an important advantage of the porosimetry method.

\section{Acknowledgements}

The Nankai Mudstone core samples were provided by the Integrated Ocean Drilling Program (IODP). Part of these works were supported by Grants-in-Aid for Scientific Research 25287134 (JSPS), Japan.

\section{References}

[1] Schön, J.H. (1998) Ch. 2, Pore Space Properties: Porosity, Specific Internal Surface, and Permeability, 2nd Edition. Handbook of Geophysical Exploration, Seismic Exploration, Vol. 18, Pergamon, Netherlands, 23-58.

[2] Franklin, J.A. (1979) Suggest Methods for Determining Water Content, Porosity, Density, Absorption and Related Properties and Swelling and Slake-Durability Index Properties. International Journal of Rock Mechanics and Mining Science \& Geomechanics Abstracts, 16, 141-156.

[3] Blum, P. (1997) Ch. 2, Moisture and Density (by Mass and Volume), in Physical Properties Handbook: A Guide to the Shipboard Measurement of Physical Properties of Deep-Sea Cores. ODP Technical Notes, 26, 2-1-2-15.

[4] American Society for Testing and Materials (1999) Standard Test Method for Determination of Pore Volume and Pore Volume Distribution of Soil and Rock by Mercury Intrusion Porosimetry, Designation D 4404-84 (Reapproved 1992). Annual Book of ASTM Standards, 04.08, 588-592.

[5] Expedition 314 Scientists (2009) Expedition 314 Site C0006. In: Kinoshita, M., Tobin, H., Ashi, J., Kimura, G., Lallemant, S., Screaton, E.J., Curewitz, D., Masago, H., Moe, K.T., and the Expedition 314/315/316 Scientists, Proc. IODP, 314/315/316, Integrated Ocean Drilling Program Management International, Inc., Washington DC.

[6] Lin, W., Tadai, O., Hirose, T., Tanikawa, W., Takahashi, M., Mukoyoshi, H. and Kinoshita, M. (2011) Thermal Conductivities under High Pressure in Core Samples from IODP NanTroSEIZE Drilling Site C0001. Geochemistry, Geophysics, Geosystems, 12, Q0AD14. 